\title{
Photonic Crystal Defect Micnocavities with Indium Arsenide Quantum Dots
}

\author{
'Tomoyuki Yoshic, Oskar l'ainter and $\Lambda \mathrm{xcl}$ Scherer \\ Department of Flectrical linginteering, Califomia Institute of Technology \\ 1201 L. California Blvd., MCl36-93, Pasadena C $\triangle 91125$ \\ I'FI :626-395-2207, liAX:626-683-9060, L-mail: yoshie(a)caltech.edu
}

Diana Huffaker and Dennis Deppe

Microclectronics Research Center, Depariment of Llectrical and Computer Enginecring, 'The University of Texas at Austin, Austin, TX 78712-1084

Strong atom-photon intcraction in a small cavity was predicted by Purcell to enhance spontaneous emission [1]. The radiation process can be more efficient than that in free space because of the confinement provided by high reflection mirrors of the cavity. Contemporary nanofabrication technology allows us to construct solid state microcavities such as micropillats [2,3], microdisks [4], or $\mathrm{AlO}_{\mathrm{x}}$-apertured microcavities [5]. Such cavitics have very high quality factor $Q$, but the modal volume $V$ is still big relative to $(\lambda / \mathrm{n})^{3}$ where $\lambda$ and $\mathrm{n}$ are the resonance wavelength and refractive index. 'l'herefore Purcell's factor, the cavity-related paraneter, which is proportional to $Q(\lambda / \mathrm{n})^{3} / V$ is limited by the large modal volume coefficient $V /(\lambda / \mathrm{n})^{3}$. In order to clearly sce the cavity QED effects, it is, therefore, crucial to obtain small relative modal volume cocfficient, too. For the above solid state microcavities, quantum dots as well as single quantum dot are often used as emission sources due to the narrow linewidth emission which can fit well to the cavity resonance.

We have recently demonstrated lasing from photonic crystal defect cavity in the $1.5 \mu \mathrm{m}$ telecommunication wavelength range [6]. The 2-1) photonic crystal defect cavity is expected to combine moderately high quality factor with relatively small modal volumes, and this provides significant advantage over the above microcavities[7]. The defect cavity in which an air hole is removed from two dimensional haxagonally arrayed photonic crystal has a $C_{60}$ symmetry. Liven if we shrink the defect size until the higher modes are eut off, some modes are allowed to exist in the photonic bandgap. However, by reducing the symmetry to $C_{2 *}$, the modes can be detuned and only one mode could survive in a forbidden bandgap as a defect mode. In this report, we describe the emission from two dimensional photonic crystals that contain an InAs QDs active laycr.

The epitaxial layers were grown on (001) (raAs by molecular beam epitaxy. The In $\Lambda$ s QDs layer is clad by $\Lambda 1_{0.15} \mathrm{Gia}_{0.85} \Lambda \mathrm{s}$ layers on a top of $0.4 \mu \mathrm{m}$ AlAs/Aly $\left(\mathrm{ia}_{1-y} \Lambda \mathrm{s}\right.$ superlattice where $\mathrm{y}$ is close to 1. The $(\mathrm{g} a \Lambda \mathrm{s} / \Lambda \mathrm{l}$ ras $\Lambda \mathrm{s}$ cap layers are added on the top at last. The cavity thickness is designed to be around $0.2 \mu \mathrm{m}$. The patterns of hexagonal arrayed photonic crystal defect cavity was preciscly transferred into PMMA resist by $1: 3$ lithography system with ficld emission electron microscope. The photonic crystal has ten layers with a single defect on the center. To reduce the symmetry to $C_{2 v}$ and lift the degeneracies of modes in addition to raising the $Q$, modification of holes around the defect was introduced. After the lithography, the pattenis were transferred through the cavity by using $\mathrm{Cl}_{2}$ assisted $\mathrm{Ar}$ ion beam etching. The ctchiitg depth was estimated to be approximately $0.4 \mu \mathrm{m}$ from the surface. Following this anisotropic etching, the $\mathrm{AlAs} / \mathrm{Al}_{\mathrm{y}}\left(\mathrm{Fa}_{1-y} \mathrm{As}\right.$ superlattice under cavities was oxidized in steam at $400^{\circ} \mathrm{C}$ to obtain a slab structure. Figure 1 shows the schematic of the photonic crystal microcavity used in this work. I, ight parallel to surface and normal to surface is contined by the photonic crystal in the plane and the slab structure vertically, respectively.

Optical pumping was conducted at room temperature by $830 \mathrm{~nm}$ semiconductor laser diodes which was operated by the $2 \mu \mathrm{sec}$ width pulse in $3 \mu \mathrm{sec}$ period. The $830 \mathrm{~nm}$ light can be absorbed only by 
QDs layer and wetting layer. The pumping light was focused on the defect and had $6 \mu \mathrm{m}$ diameter: The resonance was detected by optical spectrum analyzer as shown in figure 2 . The pumping power is $1.5 \mathrm{~mW}$. The period and radius of photonic crystals are $345 \mathrm{~nm}$ and $205 \mathrm{~nm}$, respectively. The emission but resonance is suppressed while unprocessed sample shows broad emission ranging from $1100 \mathrm{tm}$ to $1400 \mathrm{~nm}$. When the bandwidth of detector was $1 \mathrm{~nm}$, the resonance linewidth was $1 \mathrm{~nm}$.

In summary, the coupling of In $\Lambda$ s QDs emission to the two dimensional photonic crystal defect cavity has been demonstrated for the first time and a narrow tiltered emission linewidth could be observed.

\section{REFERENCES}

[1] E. M. Purcell, Phys. Rev. 69, 681 (1946)

[2] A. Scherer, J. L. Jewell, Y. H. Lee, J. P. Harbison, and L. T. Florez, Appl. Phys. I ,ett., 55, 2724 (1989)

[3] J. M. Gerard, D. Barricr, J. Y. Marzin,, K. Kuszelewicz, L. Manin, E. Costard, V. Thierry-Mieg, aud T. Rivera, Appl. Phys. Lett., 69, 449 (1996)

[4] A. F. J. Levi, R. E. Slusher, S. L. McCall, T. Tanbun-Ek, D. I. Coblentz, and S. J. Pearton, Elect. Lett. 28, 1010, (1992)

[5] D. G. Deppc, L. A. Graham, and D. L. Huffaker, IEEE J. Quattum Electron., 35, 1502 (1999)

[6] O. J. Painter; R. K. Lee, A. Scherer, A. Yariv, J. 1). O'Brien, 1. 1). Dapkus, and 1. Kim, Science 284, $1819(1999)$

[7] O. Painter, J. Vuckovic, and A. Scherer, J. Opt. Soc. Am. B, 16, 275 (1999)

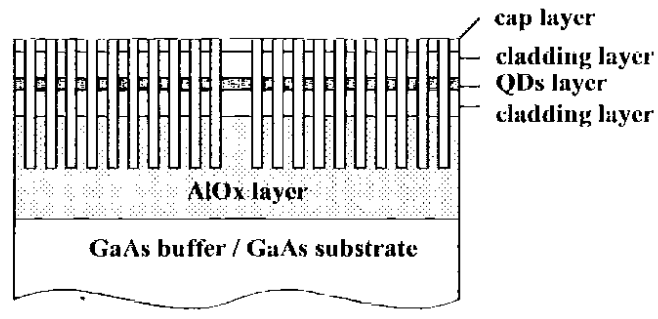

Fig. 1 schematic of photonic crystal defect cavity

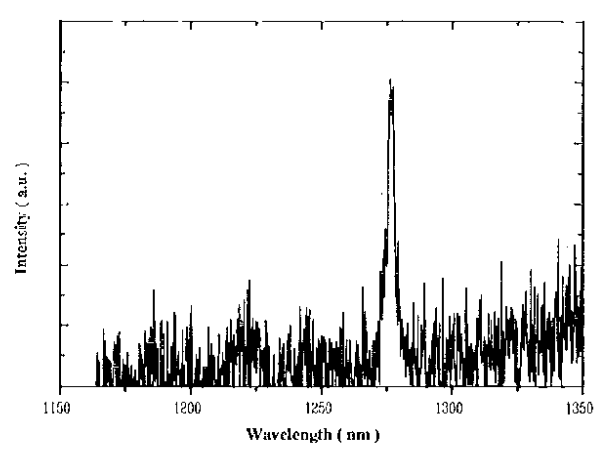

Fig. 2 photoluminescence from photonic crystal microcavity 